Article

\title{
Towards In-Situ Electron Microscopy Studies of Flash Sintering
}

\author{
Danny Schwarzbach $\left.{ }^{1} \mathbb{(}\right)$, Jesus Gonzalez-Julian $\left.{ }^{2} \mathbb{(}\right)$, Olivier Guillon ${ }^{2}$, Vladimir Roddatis ${ }^{1}(\mathbb{D}$ and \\ Cynthia A. Volkert ${ }^{1, *}$ \\ 1 Institute of Materials Physics, University of Goettingen, 37077 Goettingen, Germany \\ 2 Institute of Energy and Climate Research, Materials Synthesis and Processing (IEK-1), Forschungszentrum \\ Jülich $\mathrm{GmbH}, 52428$ Jülich, Germany \\ * Correspondence: volkert@ump.gwdg.de; Tel.: +49-551-39-5011
}

Received: 7 June 2019; Accepted: 8 July 2019; Published: 25 July 2019

\begin{abstract}
Flash sintering, a special case of electric field-assisted sintering, results in accelerated densification at lower temperatures than conventional sintering methods. However, the mechanisms remain elusive despite the wide application potential. In-situ electron microscopy studies reveal shrinkage of $\mathrm{ZnO}$ green bodies due to both heating and heating/biasing but show no obvious effect of the current on the behavior. In contrast, thin epitaxial $\mathrm{ZnO}$ films deposited on an $\mathrm{Al}_{2} \mathrm{O}_{3}$ substrate undergo a clear flash event during in-situ voltage application in the TEM, providing the first observation of flash sintering of a thin film. The specimen was captured in the high conductivity state where grain boundary motion was observed. The microscopic origins of the high conductivity state could not be detected, but may have the same underlying physical origin as the high conductivity memristive state.
\end{abstract}

Keywords: $\mathrm{ZnO}$; flash; sintering; field assisted sintering; densification; electric induced; green body; oxide ceramic powders; thin films

\section{Introduction}

A wide range of studies have shown a dramatic effect of applied electric field or current on the sintering behavior of oxide ceramic powders. A special case of this electric field-assisted sintering is so-called flash sintering (FS). It was first reported in 2010 by Cologna et al. [1], who showed that an external electrical field caused the sintering process to happen within seconds and at much lower temperatures than in the absence of a field. The main characteristic of FS is the flash event, which is characterized by a runaway electrical resistivity drop [1,2], rapid densification [1] and photoemission [3,4] once a sufficiently high electrical field and temperature are reached in the sample. The flash phenomenon has been observed in many different inorganic compounds. A few recent examples include: $\mathrm{Al}_{2} \mathrm{O}_{3}$ [5,6]; $\mathrm{TiO}_{2}$ [7]; $\mathrm{BaTiO}_{3}[8,9]$; doped $\mathrm{CeO}_{2}$ [10-13]; $\mathrm{ZrO}_{2}: 3 \mathrm{~mol} \%$ and $8 \mathrm{~mol} \%$ $\mathrm{Y}_{2} \mathrm{O}$ [1,14-16]; $\mathrm{SnO}_{2}$ [17]; and $\mathrm{ZnO}$ [18-25].

The mechanisms accounting for FS remain elusive despite its generality and wide application potential. Most often, the flash event is attributed to Joule heating [26,27]. However, opinions are divided on whether Joule heating alone can account for the fast densification, photoemission and the drop in electrical resistivity. Some investigations claim that the effect requires the creation of Frenkel defects $[3,28]$, while others suggest that the reason lies in the rapid heating process and the resulting destabilization of grain boundaries [29,30]. Another explanation relies on the formation of a percolating, high diffusion path along a transient liquid film on the powder particle surfaces, generated by inhomogeneous temperature distributions [31-33]. 
In this work, we focus on ceramic $\mathrm{ZnO}$, an abundant, safe, inexpensive and relatively easy to process model material for many different kinds of applications such as thermoelectrics, electronics, optoelectronics and laser technology $[34,35]$. ZnO shows a strong effect of electric field and current on sintering, particularly with the addition of water vapor and specific dopants $[18,36,37]$. For example, photoluminescence showed the clear effect of applied current on defect concentrations in sintered $\mathrm{ZnO}$ [25]. It has also been found that the heating rate plays a significant role when trying to sinter zinc oxide at lower temperatures [38,39]. The greatest improvements in the sintering of $\mathrm{ZnO}$ were achieved by Dargatz et al. by injecting deionized water into compact $\mathrm{ZnO}$ green bodies [40], and by Nie et al. by purging the system with wet $\mathrm{Ar}+5 \mathrm{~mol} \% \mathrm{H}_{2}$ gas for $1 \mathrm{~h}$ before starting the FS experiment [20]. In both cases, a nominal density of $\sim 98 \%$ of the theoretical density could be achieved at room temperature [20] and a furnace temperature of $400{ }^{\circ} \mathrm{C}$ [40].

Using in-situ scanning (SEM) and transmission electron microscopy (TEM), we aimed to gain insight into the atomic origins of sintering behavior, as well as into the high conductivity states that occur in conjunction with flash events during field-assisted sintering. The sintering dynamics of $\mathrm{ZnO}$ green bodies and thin films were investigated with and without applied electrical field, and with and without applied heating. Specifically, we used in-situ electron microscopy to study the evolution of microstructure and morphology, including grain/void morphology, segregation, and precipitation, both with and without applied fields in vacuum. The in-situ TEM sintering studies allowed us to detect atomic scale rearrangements near the sintering boundaries. In-situ SEM allows the general changes in morphology and chemical composition to be tracked. In order to directly compare the SEM and TEM results, we used the same commercially available biasing-heating MEMS (micro-electro-mechanical system) chips (DENSsolutions). This required constructing a special holder to mount the TEM chips in the SEM chamber.

The present study details the use of pre-sintered green body material and thin films to achieve FS conditions inside the microscope. It highlights the challenges of using green bodies to prepare suitable specimens and proposes that thin film systems are more suitable for the high-resolution studies needed to decipher the atomic scale origins of the flash effect.

\section{Materials and Methods}

$\mathrm{ZnO}$ is a n-type semiconductor ceramic with a wide band gap $(3.37 \mathrm{eV})$ and high exciton binding energy $(60 \mathrm{meV})$ belonging to the space group P63mc $(\mathrm{a}=0.325 \mathrm{~nm}, \mathrm{c}=0.521 \mathrm{~nm})$. Values of electrical conductivity depend strongly on preparation conditions [41] and annealing ambient [42], but typically lie in the range of $10^{-4}-10 \mathrm{~S} / \mathrm{cm}$ for the temperature range used in this study.

\subsection{Green Body Specimen Preparation}

$\mathrm{ZnO}$ powder with a purity of $>99.99 \mathrm{wt} \%$ was uniaxially pressed into green bodies with densities between $50 \%$ and $70 \%$ [25] using a process detailed in [43]. The use of additional chemicals for binding during sintering was avoided since it was found in initial studies to lead to extreme contamination during TEM investigations. X-ray diffraction peak positions ( $\theta-2 \theta$ analysis, Bruker D8, $\mathrm{Cu} \mathrm{K} \alpha$ radiation) and relative intensities are in quantitative agreement with the crystallographic database [44] (Figure 1a). A Scherrer fit to individual peaks gives a mean particle size of ca. $110 \mathrm{~nm}$, in good agreement with SEM images (Figure 1b). 


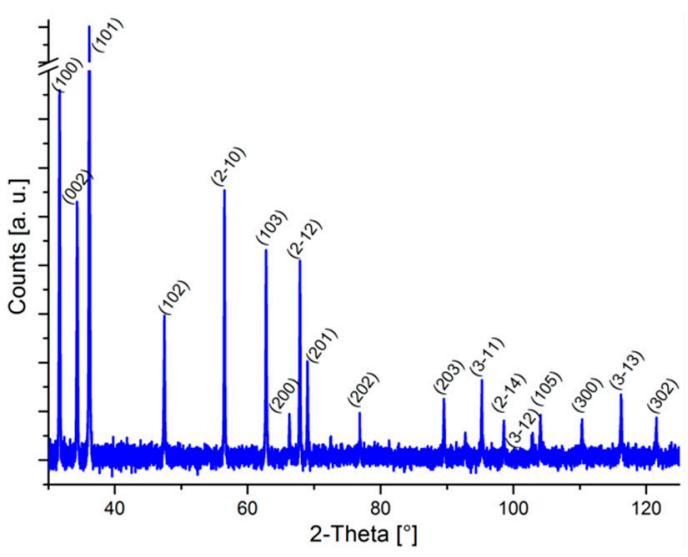

(a)

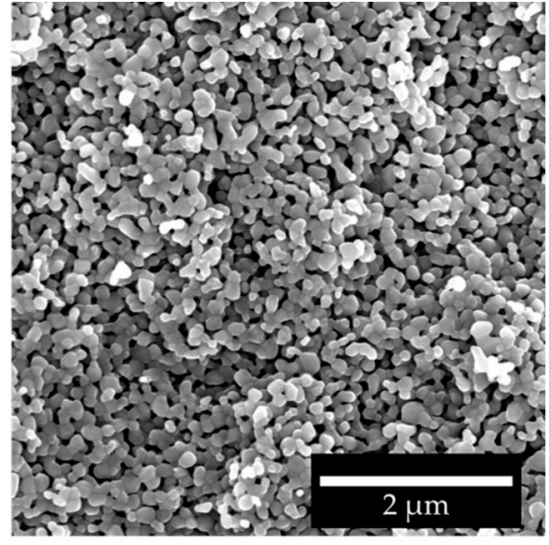

(b)

Figure 1. ZnO green body. (a) Theta-2-Theta X-ray powder diffraction measurement reveals the expected polycrystalline behavior. (b) SEM image of the surface of the pressed green body specimen.

In-situ electron microscopy specimens were prepared from the $\mathrm{ZnO}$ green body material using a combined precision ion polishing system/focused ion beam (PIPS/FIB) method. First, a $3 \mathrm{~mm}$ diameter disc was cut from the green body sample, glued onto a polishing holder with mounting wax and ground down to a thickness between 30 and $60 \mu \mathrm{m}$ (Minitech 233 from Presi). Afterwards, the disc was removed from the polishing holder using acetone and attached to a $\mathrm{Cu}$ grid with epoxy resin. The sample was further thinned using $4 \mathrm{keV}$ Ar ion milling (Gatan PIPS Model 691) until a hole was formed in the middle of the sample (Figure 2a). The ion beam damage was then partially removed by a sequence of shorter milling steps at reduced ion beam energies: $3 \mathrm{keV}$ for $2 \mathrm{~min}$; $2 \mathrm{keV}$ for $3 \mathrm{~min}$; 1 $\mathrm{keV}$ for $5 \mathrm{~min}$; $0.5 \mathrm{keV}$ for $10 \mathrm{~min}$.

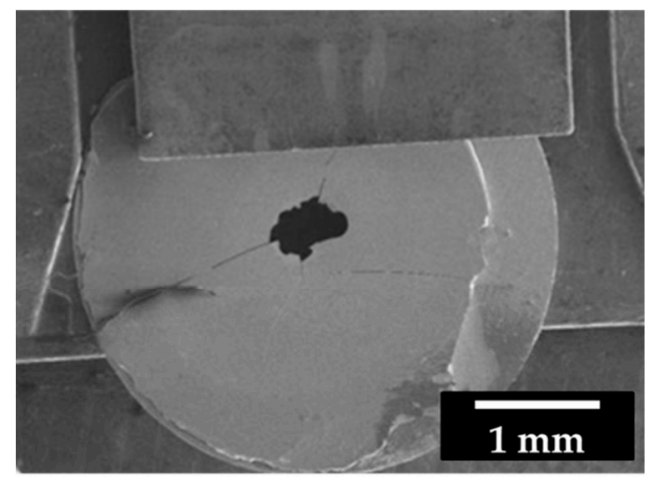

(a)

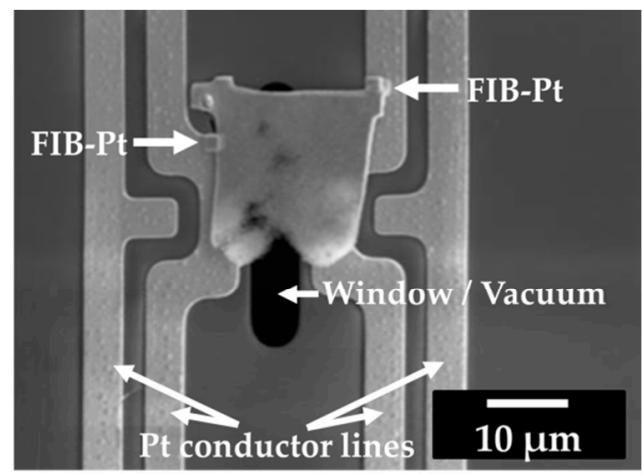

(b)

Figure 2. ZnO green body specimen. (a) Precision ion polishing system (PIPS) prepared disc-shaped sample, and (b) the focused ion beam (FIB) mounted lamella, which was cut from the edge area of the PIPS generated hole in (a). The FIB-Pt patches, indicated with arrows, attach the ZnO lamella to the $\mathrm{SiN}$ membrane and Pt conductor lines of the DENSsolutions biasing-heating chip.

The disc-shaped sample was then mounted in the focused ion beam (FIB) microscope, where a ca. 10-30 $\mu \mathrm{m} \times 10 \mu \mathrm{m}$ lamella was cut out of the area near the hole and attached to a biasing-heating MEMS chip (DENSsolutions) with FIB-Pt patches (Figures $2 b$ and A1). The thinnest region of the lamella was placed over the window in the SiN membrane of the MEMS-based chip. The Pt deposition process results in a thin layer of contaminants all over the surrounding surfaces. 


\section{2. $\mathrm{ZnO}$ Thin Films}

Epitaxial $\mathrm{ZnO}$ films were grown on (0001) $\mathrm{Al}_{2} \mathrm{O}_{3}$ substrates by a metalorganic aerosol deposition (MAD) technique at an oxygen partial pressure of 0.2 bar $[45,46]$. The precursor, acetylacetonate (acac) of $\mathrm{Zn}^{2+}$, was dissolved in dimethylformamide (DMF) to obtain a solution which is sprayed onto the substrate using a pneumatic nozzle, which produces drops with a mean diameter of $\sim 20 \mathrm{~nm}$ at characteristic gas flows of about $10-151 / \mathrm{min}$. The $\mathrm{Al}_{2} \mathrm{O}_{3}$ substrate was heated to $670{ }^{\circ} \mathrm{C}$, leading to a deposition rate of $\sim 30 \mathrm{~nm} / \mathrm{min}$. X-ray diffraction studies of the resultant $\mathrm{ZnO}$ thin films revealed strong in-plane and out-of-plane texture, and the narrow peaks revealed good crystal quality (Figure 3a). A representative SEM image of the film surface shows extensive roughness (Figure 3b).

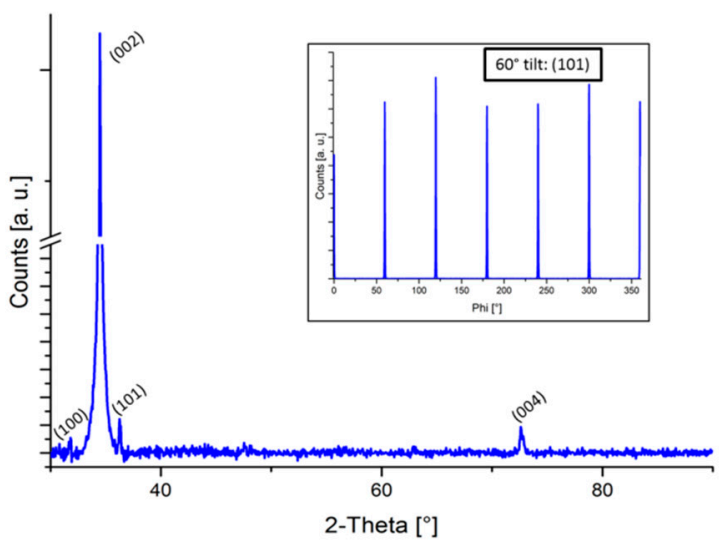

(a)

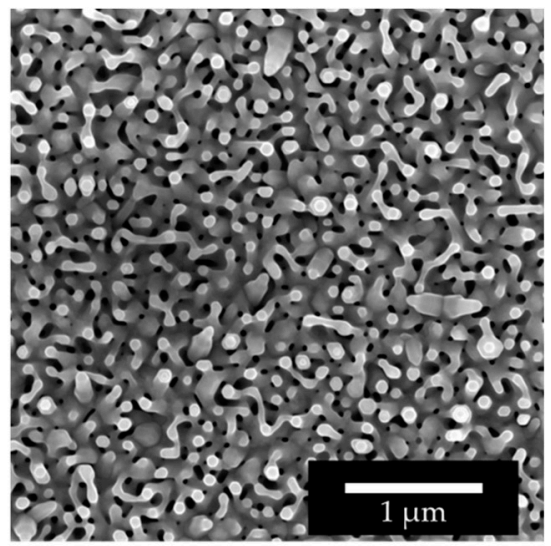

(b)

Figure 3. $100 \mathrm{~nm}$ thick $\mathrm{ZnO}$ thin film on $\mathrm{Al}_{2} \mathrm{O}_{3}$. (a) Grazing incidence theta-2-theta X-ray diffraction reveals a strong (001) out-of-plane texture. The phi scan in the inset reveals (101) 6-fold symmetry as expected from a single crystal. (b) SEM image of the surface of the thin film showing high roughness at ca. $100 \mathrm{~nm}$ length scale.

Thin film TEM lamella preparation and the mounting on the MEMS chip were all done in the FIB without any use of the PIPS. The FIB was used to cut a $\mu \mathrm{m}$ size block of material from the thin film, which was then transferred and mounted on the MEMS chip using a micromanipulator and Pt deposition. The advantage of this method is that the necessary thinning procedure takes place after the specimen is fixed with FIB-Pt to the MEMS chip, allowing contamination from the Pt deposition process to be completely removed from the sample surface. We used a similar method to [47] (Table A1). To reduce ion beam damage during thinning of the $\mathrm{ZnO}$ layer, photoresist (alkali-stable positive resist SX AR-P 5900/4) was first coated on the layer using a lithography process. This coating is electrically insulating and does not disturb the later flash experiments. The mounted lamella is shown in Figure 4. The 50 to $100 \mathrm{~nm}$ thick lamella lies over a window in the SiN chip membrane (Figure 4a). A TEM image shows that the film consists of columnar grains with ca. $100 \mathrm{~nm}$ in-plane diameters (Figure 4b). 


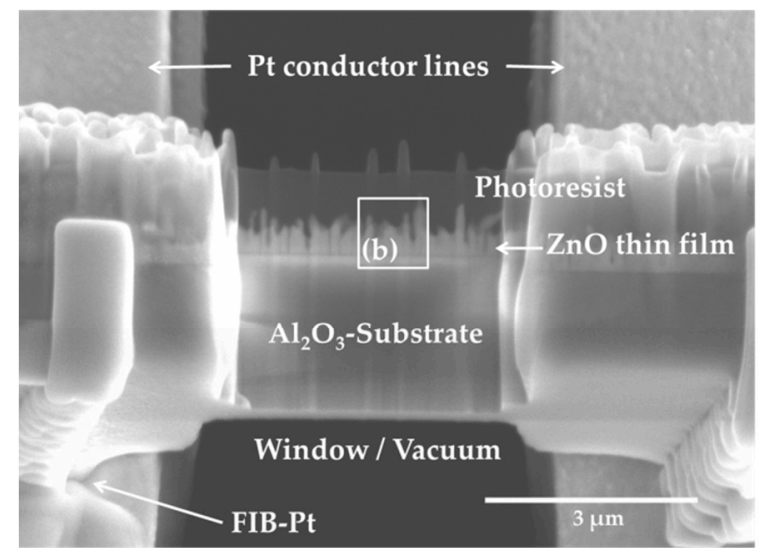

(a)

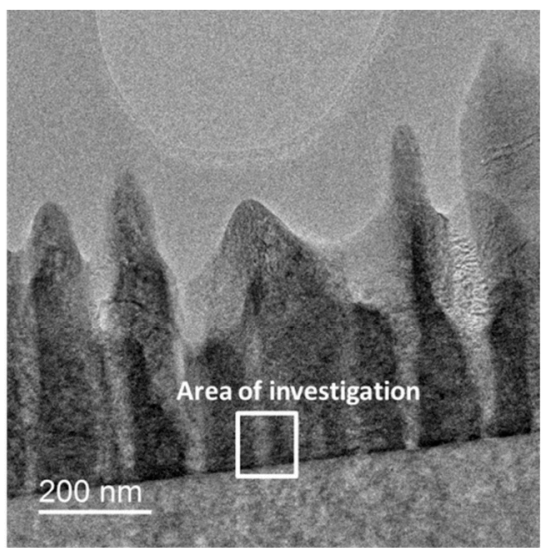

(b)

Figure 4. $\mathrm{ZnO}$ thin film TEM specimen. (a) Photoresist coated $\mathrm{ZnO}$ thin film on $\mathrm{Al}_{2} \mathrm{O}_{3}$ substrate lamella, thinned and mounted on a DENSsolutions MEMS chip using FIB. (b) Lamella at higher magnification indicating the area used for in-situ TEM examination.

\subsection{In-Situ Test Setup}

In all cases, the specimens were mounted on a DENSsolutions 6 contact MEMS heating-biasing chip as shown in Figure A1. These chips are used in a heating/biasing holder capable of applying and withstanding temperatures up to $1200{ }^{\circ} \mathrm{C}$ (DENSsolutions Lightning D7 + in-situ TEM holder). The holder has six electrical contacts, four being used for biasing and the other two for sample heating using a spiral coil [48]. A Keithley 2601A is used to apply the bias to the specimen and to measure voltage and current in two-point geometry. The resistance of the electrical supply lines can be neglected as it is very low compared to the resistance of the sample [47]. During an in-situ experiment the sample is first heated to a desired temperature and a voltage ramp is applied to the chip until the current limit is reached, which is applied to avoid run-away failures and to catch the specimen in a high conductivity state during FS. The current density can be estimated from the current/specimen cross-section and including the relative density of the green body. The electrical field $\mathrm{E}$ is simply calculated as voltage divided by the distance between Pt-contacts, which lies between $8.8 \mu \mathrm{m}$ and 10.5 $\mu \mathrm{m}$ for the experiments performed here.

In-situ and ex-situ experiments were performed in an image $\mathrm{C}_{S}$ corrected FEI Titan operating in TEM mode at $300 \mathrm{kV}$ with a built-in Gatan GIF Quantum, Dual EELS capability, and monochromator. Initial specimen characterization was performed on a FEI Tecnai $\mathrm{G}^{2}$ Spirit at $120 \mathrm{kV}$. In-situ SEM measurements were performed in a FEI Nova NanoSEM at $30 \mathrm{kV}$. For this we used a self-constructed SEM holder that allows full use of the DENSsolutions MEMS chips (Figure 5). By applying the same biasing and heating conditions as in the TEM, control experiments can be performed to observe the FS method in a much larger field of view. This allows the entire mounted $\mathrm{ZnO}$ specimen, including thicker regions as well as on the MEMS contact wires to be observed and to investigate changes in structure and possible short or open circuits. Both SEM and STEM imaging are possible. The background chamber pressure was in the range of $10^{-8} \mathrm{mbar}$ in the TEMs and $10^{-6} \mathrm{mbar}$ in the SEM during the experiments. 


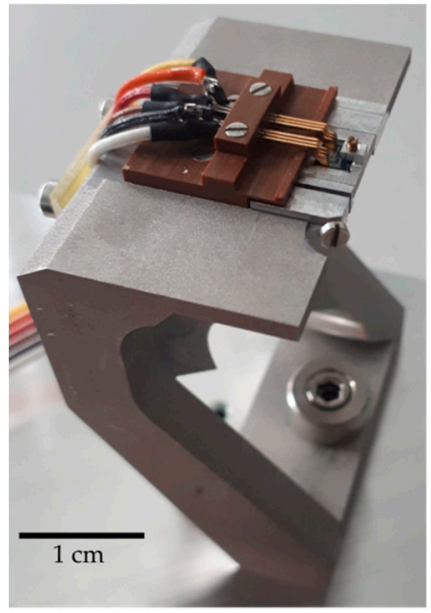

(a)

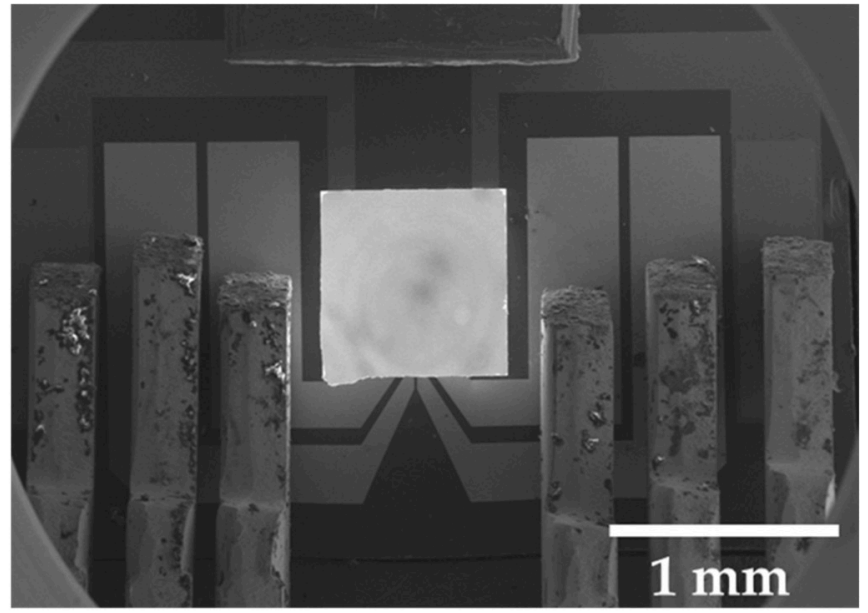

(b)

Figure 5. (a) Holder for mounting and using DENSsolutions 6-contact biasing-heating MEMS chips during reflection or transmission imaging in the SEM. (b) SEM image of a mounted test chip without SiN membrane.

\section{Results}

In-situ sintering experiments were performed on the pre-sintered $\mathrm{ZnO}$ green body and thin film specimen, both with and without applied currents and heating. The pre-sintered green body specimens were examined in both SEM and TEM while the thin film was only studied in the TEM.

\subsection{ZnO Green Body Sintering}

A PIPS/FIB prepared TEM lamella of the $\mathrm{ZnO}$ green body was mounted on the biasing-heating holder and was first heated up to $400{ }^{\circ} \mathrm{C}$. TEM imaging shows that the green body is stable at this temperature (Figure 6a), with no evidence of contamination, phase formation or morphology changes even after $10 \mathrm{~min}$ of imaging at $120 \mathrm{keV}$. The polycrystalline nature of the green body is confirmed by selected area diffraction (inset of Figure 6a). A voltage ramp of $0.05 \mathrm{~V} / \mathrm{s}(47.59 \mathrm{~V} / \mathrm{cm} \mathrm{s})$ was then applied to the specimen until a current limit of $0.65 \mathrm{~mA}\left(1.49 \mathrm{~V}, 1419.05 \mathrm{~V} / \mathrm{cm}, 4243.77 \mathrm{~A} / \mathrm{cm}^{2}\right)$ was reached.

Immediately after reaching the current limit, small precipitates appear on the surface of the $\mathrm{ZnO}$ green body. Furthermore, the green body begins to shrink but without any grain growth (Figure 6b). The shrinkage is accompanied by loss of material rather than by a decrease in porosity, leading to a decrease in density, in contradiction to the usual sintering behavior. Further increases in the electric field and current lead to further shrinkage of the $\mathrm{ZnO}$.

An EDX spectrum (Figure $6 \mathrm{~d}$ ) obtained from the indicated region of the heat and current-treated specimen (Figure $6 \mathrm{~b}$ ) shows the presence of $\mathrm{Zn}$, oxygen and $\mathrm{Pt}$, suggesting that the precipitates are Pt-based. The ratio of the $\mathrm{Zn}$ to oxygen peaks was not significantly different from the ratio for the initial specimens. Thus, the observed loss of material presumably involves both desorption of oxygen and sublimation of $\mathrm{Zn}$, likely aided by electron beam induced decomposition of the $\mathrm{ZnO}$ in the vacuum. All other peaks come from the MEMS chip and TEM holder, as confirmed by comparison with EDX spectra taken under the same conditions but without a lamella. 


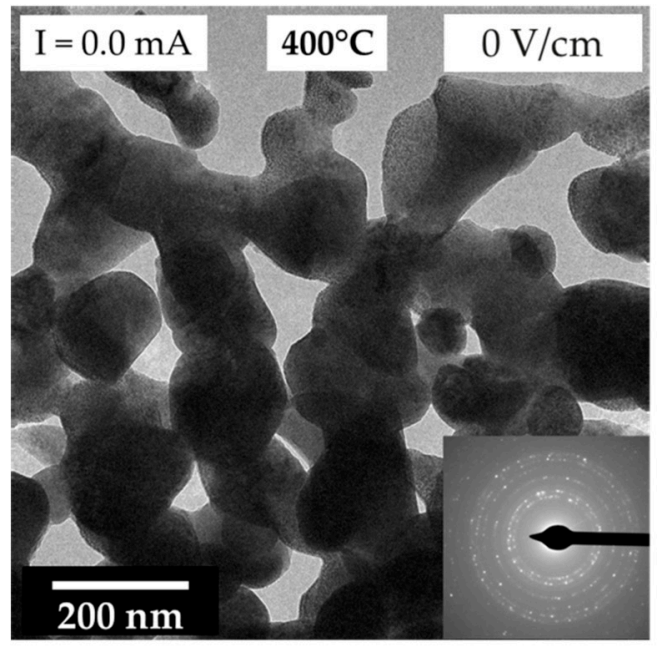

(a)

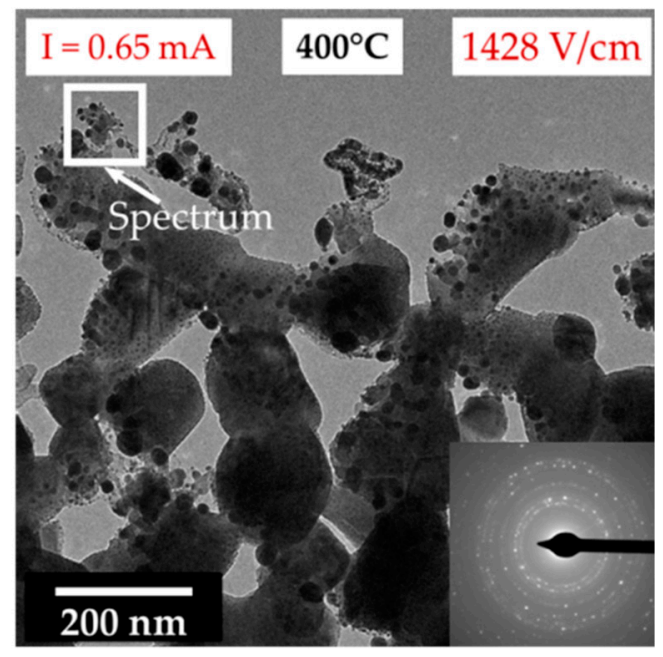

(b)

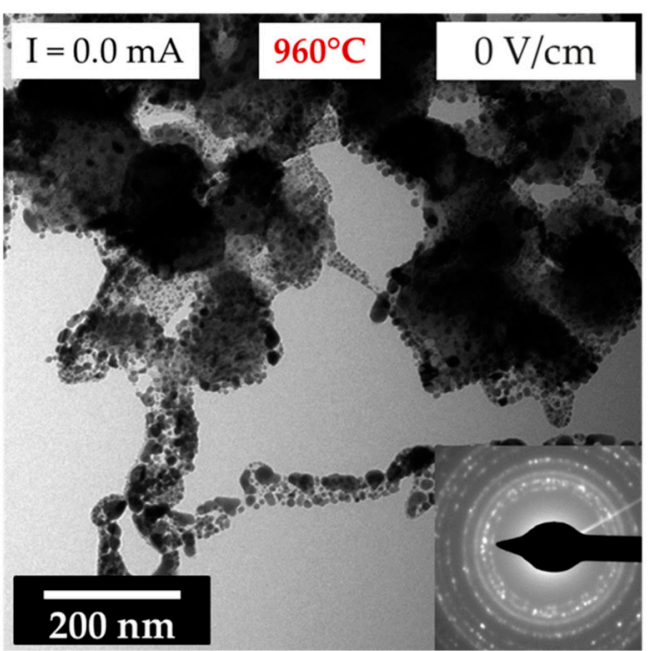

(c)

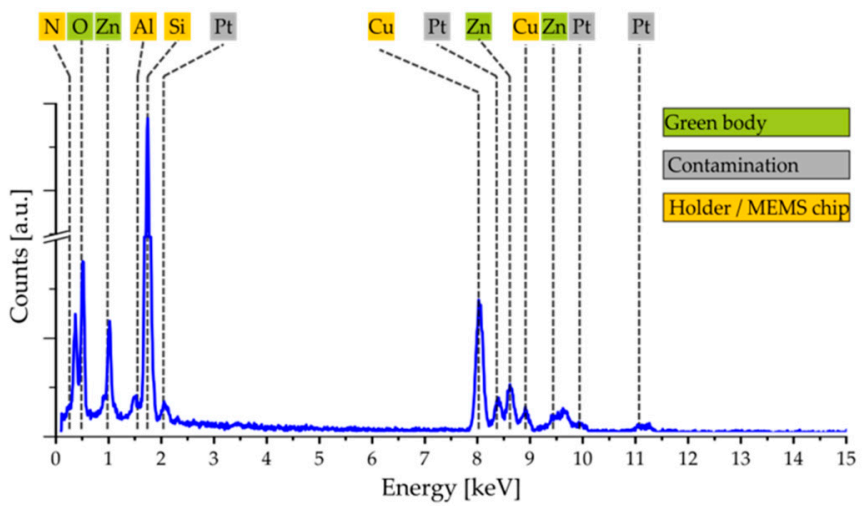

(d)

Figure 6. $\mathrm{ZnO}$ green body shrinkage in TEM. (a) The green body is stable at $400{ }^{\circ} \mathrm{C}$, (b) but shrinks and forms precipitates under an applied field and current. (c) Similar behavior is observed upon heating above $800{ }^{\circ} \mathrm{C}$ without current. (d) EDX spectra of the marked region in (b), revealing Pt contamination of the sintered material. 
To distinguish between the effects of current and temperature, a temperature ramp of $10^{\circ} \mathrm{C} / \mathrm{min}$ was applied without additional field or current to a PIPS/FIB ZnO green body specimen. After a temperature of $720^{\circ} \mathrm{C}$ was reached, precipitates began to form on the surface of the green body. With increasing temperature, they grew in size and coalesced. Shrinkage of the $\mathrm{ZnO}$ and material loss without grain growth set in starting from $800{ }^{\circ} \mathrm{C}$ (Figure 6c). This behavior, which is similar to the sample tested at $400{ }^{\circ} \mathrm{C}$ with current, suggests that the observed precipitation and shrinkage are predominately due to the temperature, and that the current only contributes through Joule heating. The slightly less homogeneous distribution of precipitates on the surface of the sample with applied current is possibly due to heterogeneous temperatures from Joule heating.

A SEM investigation of a PIPS/FIB prepared lamella from the $\mathrm{ZnO}$ green body showed similar behavior to what was observed in the TEM. The green body is stable at a temperature of $400{ }^{\circ} \mathrm{C}$ (Figure 7a), with no evidence of contamination, phase formation or morphology changes even after 10 min of imaging at $30 \mathrm{keV}$. A voltage ramp of $0.05 \mathrm{~V} / \mathrm{s}(50 \mathrm{~V} / \mathrm{cm} \mathrm{s})$ was applied to the specimen while a two-contact resistance measurement was performed. Upon obtaining an electrical field of $1250 \mathrm{~V} / \mathrm{cm}$ $\left(1.1 \mathrm{~V}, 4.78 \times 10^{-4} \mathrm{~A}, 2.63 \times 10^{3} \mathrm{~A} / \mathrm{cm}^{2}\right)$, shrinkage of the specimen begins to set in (Figure $7 \mathrm{~b}$ ). The shrinkage is very clear when an electric field of $4045.45 \mathrm{~V} / \mathrm{cm}\left(3.56 \mathrm{~V}, 9.87 \times 10^{-4} \mathrm{~A}, 3.51 \times 10^{3} \mathrm{~A} / \mathrm{cm}^{2}\right)$ is reached (Figure 7c). At $E \geq 4056.81 \mathrm{~V} / \mathrm{cm}\left(3.57 \mathrm{~V}, 9.85 \times 10^{-4} \mathrm{~A}, 5.41 \times 10^{3} \mathrm{~A} / \mathrm{cm}^{2}\right)$, the $\mathrm{ZnO}$ specimen reacts with the Pt conductors on the chip, locally melting the conductor line and resulting in an open circuit (Figure 7d). It is very difficult to estimate the change in density of the specimen due to heat and current treatment, so, it is not clear if the shrinkage is the result of an increase in relative density (the usual case for sintering) or due to material loss to the SEM vacuum.

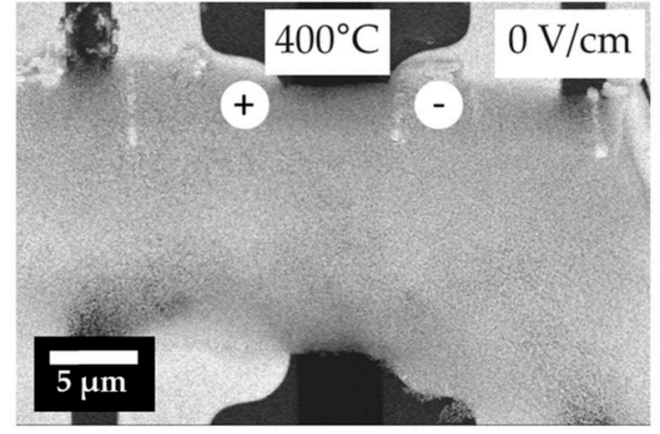

(a)

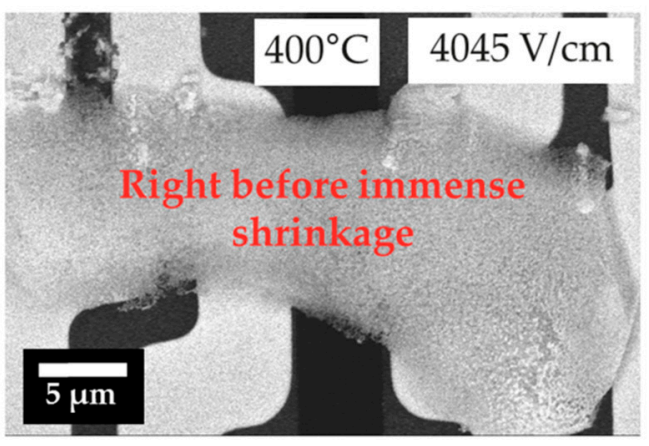

(c)

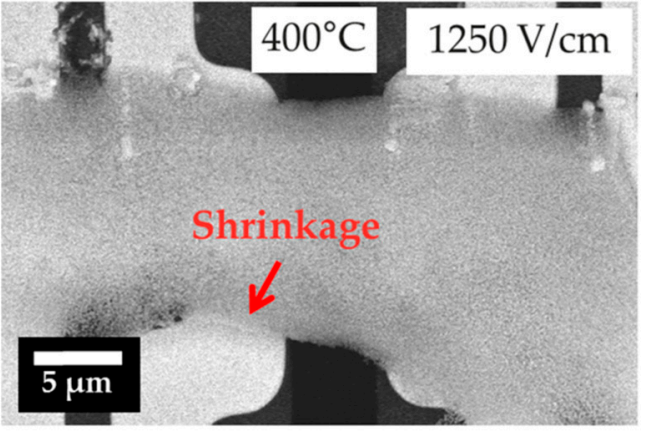

(b)

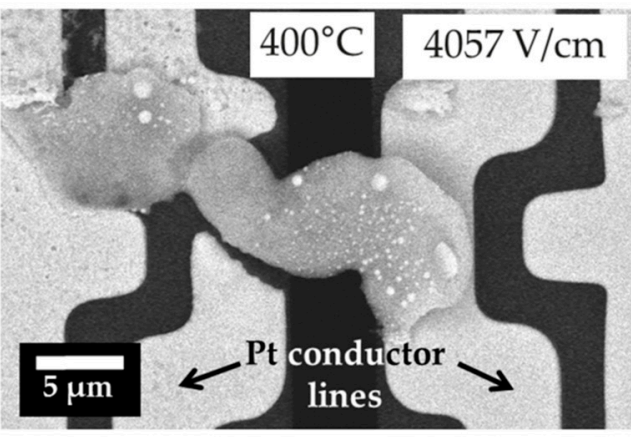

(d)

Figure 7. ZnO green body shrinkage in SEM. (a) The green body is stable at $400{ }^{\circ} \mathrm{C},(\mathbf{b}-\mathbf{d})$ but shrinks and forms precipitates under an applied field and current, and (d) eventually reacts with a Pt-conductor line.

EDX mapping obtained from the middle area of the $\mathrm{ZnO}$ lamella (Figure $8 \mathrm{a}-\mathrm{c}$ ) confirms that the precipitates are $\mathrm{Pt}$-rich and $\mathrm{Zn}$-poor. In contrast to the observations in TEM, the ratio of the oxygen 
to $\mathrm{Zn}$ EDX peaks from the ZnO lamella increased significantly due to heat and current treatment, suggesting that the relative oxygen content of the specimen increases. Reasons for this are unclear at this time, however, it does suggest that oxides with higher oxygen content may be formed while $\mathrm{Zn}$ is preferentially evaporated. A video of the in-situ experiment is available in the Supplementary Materials.

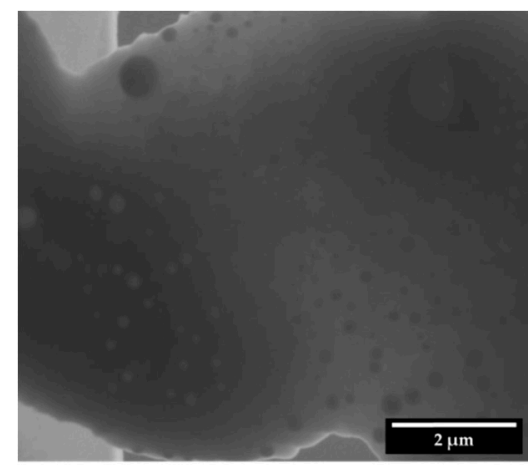

(a)

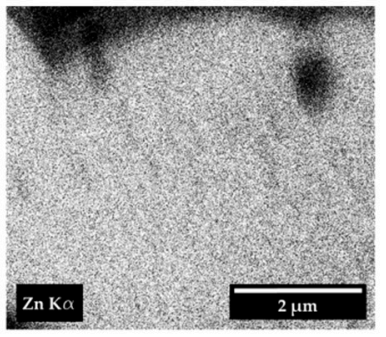

(b)

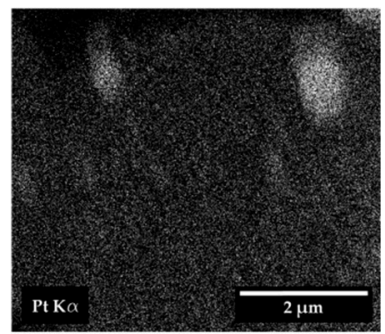

(c)

Figure 8. EDX map of $\mathrm{ZnO}$ green body after shrinkage at $400{ }^{\circ} \mathrm{C}$ with applied electric current. (a) SEM image, (b) Zn EDX signal, and (c) Pt EDX signal in sintered ZnO lamella.

\section{2. $\mathrm{ZnO}$ Thin Films}

The TEM biasing experiment was performed on a FIB prepared thin film without applied heating in order to minimize the temperatures reached in the $\mathrm{ZnO}$ due to Joule heating during in-situ testing. An electrical bias with a voltage ramp of $0.05 \mathrm{~V} / \mathrm{s}(58.14 \mathrm{~V} / \mathrm{cm} \mathrm{s})$ was applied to the specimen up to a current limit of $0.5 \mathrm{Ma}\left(2.17 \mathrm{~V}, 2.52 \times 10^{3} \mathrm{~V} / \mathrm{cm}, 3.57 \times 10^{6} \mathrm{~A} / \mathrm{cm}^{2}\right)$. The electric field (distance between electrical contacts $8.6 \mu \mathrm{m}$ ), current density (the thin film specimen cross-section is estimated as $70 \mathrm{~nm}$ $\times 200 \mathrm{~nm}$ ), power density and conductivity are shown in Figure 9 . It can be seen that the conductivity of the specimen abruptly increases, indicating the onset of a flash event, and is then captured in this high conductivity state by switching to current control. The electric field during the flash event is more than a factor of 10 larger than the fields used to generate FS in green bodies of $\mathrm{ZnO}$ at temperatures of $600{ }^{\circ} \mathrm{C}$ and above [25]. The current density with a value of $3.57 \mathrm{MA} / \mathrm{cm}^{2}$ is more than 5 orders of magnitudes higher than typical green body values [25]. This is due to the conductivity of the $\mathrm{ZnO}$ film, which starts out at ca. $0.21 \mathrm{~S} / \mathrm{cm}$ - a value at the top end of the range found in the literature [25]. It then increases dramatically during the flash event to a value of $1522 \mathrm{~S} / \mathrm{cm}$. The power density is also much larger than values experienced during flash events in green bodies. After turning the voltage back down to zero, the conductivity reverted to an intermediate value indicating that the origins of the high conductivity state are only partially reversible.

TEM imaging shows that the microstructure of the $\mathrm{ZnO}$ does not change prior to the flash event. Only a very slight drift of the image can be observed, which is attributed to bulging of the MEMS chip due to a temperature rise from Joule heating of the specimen. As soon as the flash event occurs, clear changes in microstructure are observed, in the form of shifting Moiré patterns and motion and sharpening of the grain boundaries. These continue for as long as the current is held at the high value. Two HRTEM BF images from an in-situ video (available in the Supplementary Materials) are shown in Figure 10. The facetted grain boundary moves from its initial position (Figure 10a, marked by a white arrow) a distance of approximately $4 \mathrm{~nm}$ in $160 \mathrm{~s}$ (Figure 10c). Figure 10b provides a sketch of the grain boundary geometry. Since the grain boundary is not perpendicular to the electron beam, a Moiré pattern is observed where the grains overlap, and shifts as the grain boundary moves, indicating slight relative motion of the grains. Fast Fourier Transformation of the images reveals amorphous or highly defective regions near the grain boundary that recrystallize during the experiment. 


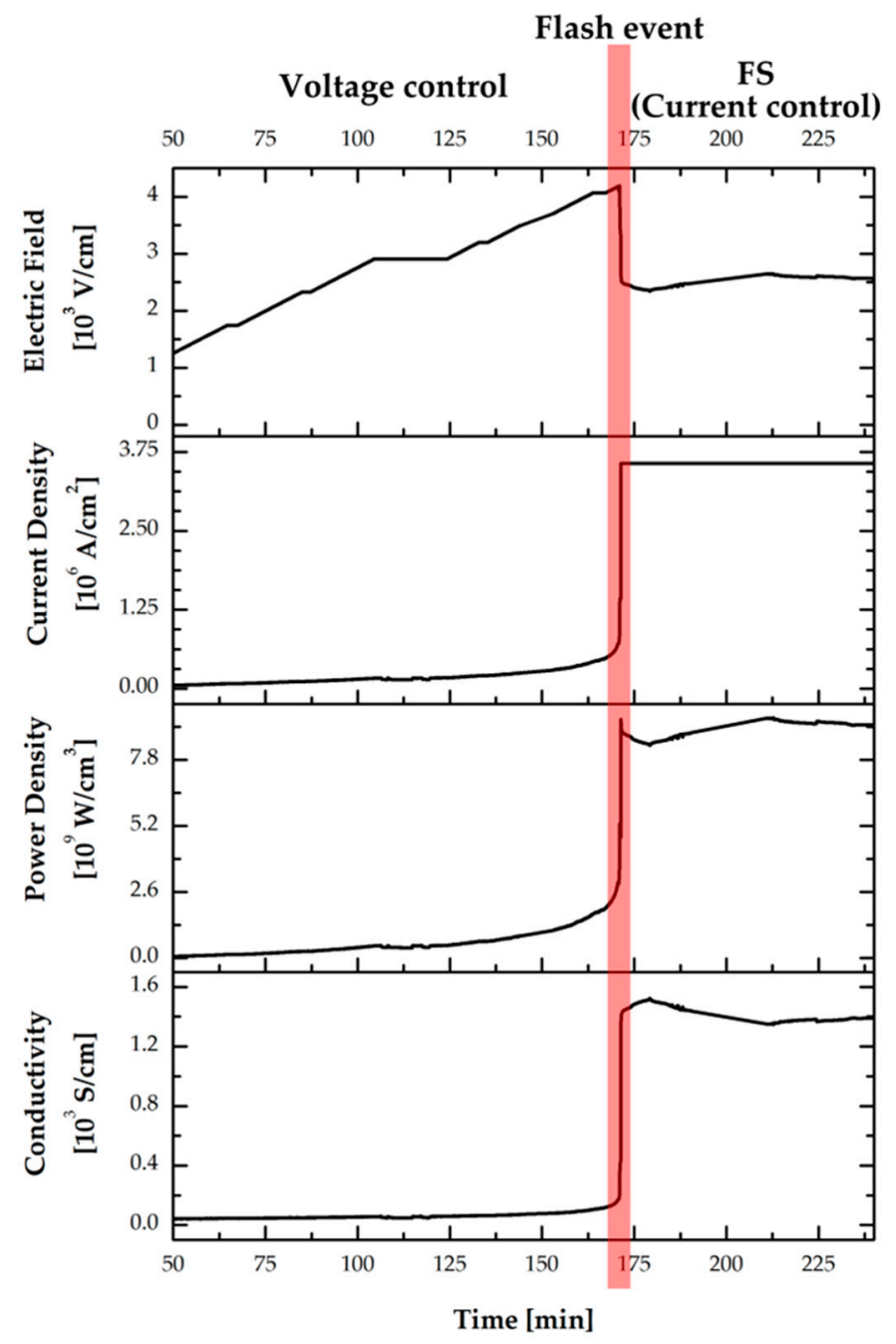

Figure 9. Time evolution of the electrical field, current density, power density and conductivity of the $\mathrm{ZnO}$ thin film during the in-situ TEM flash event. The specimen is under voltage control until the flash event occurs, when it is switched to current control and captured in the high conductivity flash event state. No additional heating was used during the experiment.

Similar rearrangements of the grain boundary were observed during the flash event throughout the $\mathrm{ZnO}$ thin film. In order to investigate the effect of the electron beam, continuous imaging was avoided in specific regions of the specimen by blanking the electron beam. Only initial and final images of grain boundaries were taken, confirming that grain boundary motion also occurs in the absence of the electron beam. 


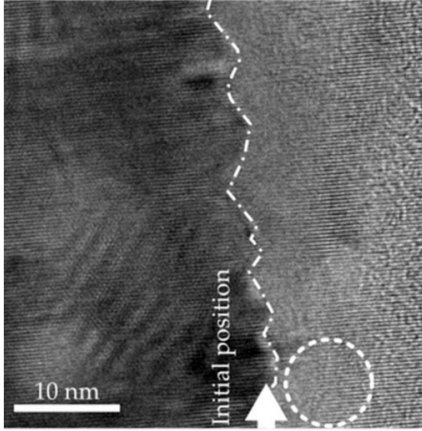

(a)

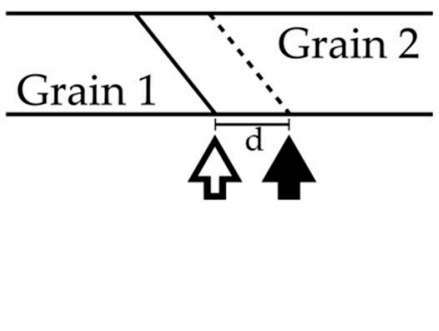

(b)

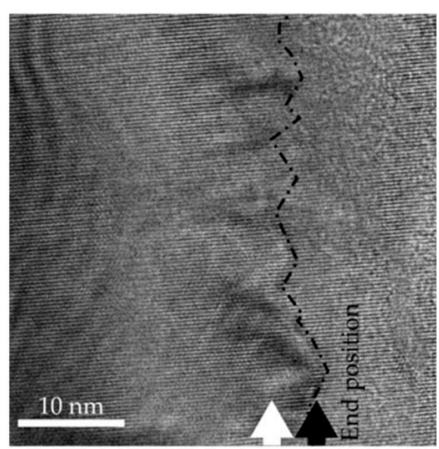

(c)

Figure 10. Grain boundary migration in a $\mathrm{ZnO}$ film during a flash event in the direction of the applied field. The field of view is near the substrate as shown in Figure $4 \mathrm{~b}$; the applied electric field and current are shown in Figure 9. No additional heating was provided to the specimen. The facetted grain boundary moves from its initial position (a) (marked by white arrow) a distance of approximately $4 \mathrm{~nm}$ in $160 \mathrm{~s}$ to the position shown in (c) (black arrow). Image (b) provides a sketch of the grain boundary structure in (a) (solid line) and (c) (dashed line). The circled region in (a) recrystallizes during the $160 \mathrm{~s}$.

\section{Discussion}

Clear shrinkage of the $\mathrm{ZnO}$ green body specimens was observed during both heating and heating/biasing experiments in the TEM and SEM, although coarsening of the grain structure was not detected. The relative specimen density after treatment was difficult to determine so that it is not clear whether shrinkage is predominately due to material loss or also includes loss of porosity, as is expected for sintering. No clear difference was found between the heating and heating/biasing experiments, indicating that the main role of the current is Joule heating. EDX results combined with observations of mass loss suggest that $\mathrm{Zn}$ and $\mathrm{O}$ are both lost from the specimen by sublimation and desorption; redistribution of oxygen may also occur [49] and affect the EDX results. Pt-based precipitates were observed to form on the $\mathrm{ZnO}$ green body specimens, presumably due to reaction with the Pt conductor lines, Pt-based patches, and the thin Pt layer formed on the sample surface during Pt deposition in the FIB. Their formation is also attributed to thermal effects since they form at sufficiently high temperatures in the absence of current. The reaction of the $\mathrm{ZnO}$ with the FIB-deposited Pt-based material makes testing of FIB-mounted specimens difficult, although switching to another FIB-deposited material might overcome this problem.

The in-situ TEM study of the $\mathrm{ZnO}$ film showed a clear flash event, as evidenced by an abrupt increase in film conductivity. We were able to capture the specimen in the high conductivity state and perform in-situ observations of the resultant grain boundary motion. However, the origins of the high conductivity state were not obvious from the images. Possible thin film liquid states at the specimen surface or at the interface to the substrate were not observed, but can be difficult to see. The generation of large populations of Frenkel defects is often proposed to explain flash sintering of bulk specimens [50], but these are also difficult to observe in the TEM and cannot be ruled out at this time. Changes in the grain boundaries seem an unlikely cause of the increased conductivity since there are single grains in some places in the lamella through-thickness, blocking a possible percolating current path. It seems likely that the high conductivity state has some similarity to the memristive state of $\mathrm{ZnO}$, which is usually attributed to electrochemical-induced oxygen vacancy migration $[49,51,52]$.

The temperature increase in the $\mathrm{ZnO}$ film due to Joule heating can be estimated from the power density (Figure 9) and sample geometry using finite element simulations. Assuming the temperature at the edges of the TEM lamella are fixed at room temperature, we estimate the maximum temperature in the $\mathrm{ZnO}$ film due to Joule heating to be between 180 and $490^{\circ} \mathrm{C}$, depending on the thickness of the TEM lamella (assumed to be between 50 and $100 \mathrm{~nm}$ ). These temperatures are all well above the 
Debye temperature for $\mathrm{ZnO}$ of $142.85^{\circ} \mathrm{C}$ [53] in accordance with a recent study [54] suggesting that the Debye temperature is the minimum possible flash sintering temperature in materials.

The predicted temperature range due to Joule heating is certainly not large enough to account for the order of magnitude increase in conductivity observed during the flash event. It is also well below the film deposition temperature of $680^{\circ} \mathrm{C}$, where the film was held for around $15 \mathrm{~min}$. It seems unlikely then that temperature alone could induce microstructural changes in the film, suggesting that the observed microstructural changes may be due to the current or the field. Nevertheless, the FIB machining introduces a variety of changes in the specimen, such as driving forces for grain boundary motion due to the creation of free surfaces, defect formation and stoichiometry changes, so that the driving force for the observed grain boundary motion is not yet clear.

The good news from our results is that a flash event could be captured in-situ in the TEM, opening up the possibility of investigating the origins of the high conductivity flash sintering state at the atomic level. Furthermore, this is the first reported observation of flash behavior in a thin film, and raises the question of the relation between flash sintering and the memristive effect observed in thin films and nanoscale structures of various materials, including $\mathrm{ZnO}[49,51,52]$. Nonetheless, many questions remain about the reasons for the observed behavior, including whether the FIB-prepared surfaces and interfaces of the $\mathrm{ZnO}$ thin film TEM specimen play a dominant role. In addition to ex-situ studies of $\mathrm{ZnO}$ thin film flash behavior, the next steps to resolve this will include high resolution post-mortem studies on conventional and flash sintered $\mathrm{ZnO}$ to detect the origins of the irreversible change in conductivity as well as to prepare better quality in-situ TEM specimens with grain boundaries perpendicular to the electron beam. These should allow higher resolution studies of atomic structure and electronic structure using electron energy loss spectroscopy.

\section{Conclusions}

In conclusion, we observed field assisted and purely thermal sintering of a $\mathrm{ZnO}$ green body using in-situ electron microscopy, but saw no obvious effect of the current on the behavior. The observations were complicated by contamination of the specimen with Pt-based precipitates as well as loss of $\mathrm{Zn}$ and $\mathrm{O}$ to the vacuum. In contrast, thin $\mathrm{ZnO}$ films deposited on an $\mathrm{Al}_{2} \mathrm{O}_{3}$ substrate underwent an abrupt increase in conductivity resulting in a clear flash event. Grain boundary motion due to the current was observed in the high conductivity state, but microscopic origins for the high conductivity state could not be detected.

Supplementary Materials: The following are available online at http://www.mdpi.com/2571-6131/2/3/36/s1, Video S1: SEM Green Body Shrinkage, Video S2: Grain Boundary Dynamics during Current Hold.

Author Contributions: Conceptualization: C.V., V.R. and O.G.; Methodology: D.S., V.R. and C.V.; Formal analysis: D.S. and V.R.; Investigation: D.S., C.V. and V.R.; Resources: C.V., O.G., J.G.-J.; Writing-original draft preparation: D.S., C.V. and V.R.; Writing-review and editing: D.S., C.V. and V.R; Visualization: D.S.; Supervision: C.V., V.R. and O.G.; Project administration: C.V., V.R. and O.G.; Funding acquisition: C.V., V.R. and O.G.

Funding: The authors are grateful for financial support by the Deutsche Forschungsgemeinschaft (VO 928/10-1, RO 5387/1-1) in the framework of the priority program SPP 1959.

Acknowledgments: The authors wish to thank Tobias Schulz, Matthias Hahn and Frank Köhler for design and preparation of the SEM MEMS holder, Volker Radisch and Ulrich Ross for the support with the FIB and TEM measurements, Jonas Lindner for his LabView expertise and the support with the electrical measurements, Vasily Moshnyaga for the use of his thin film deposition device and discussions, and Thomas Brede for the quick introduction to finite element simulations and ongoing discussions.

Conflicts of Interest: The authors declare no conflict of interest. The funders had no role in the design of the study; in the collection, analyses, or interpretation of data; in the writing of the manuscript, or in the decision to publish the results. 


\section{Abbreviations}

The following abbreviations used in this manuscript:

BF

Bright field

DMF

Dimethylformamide

EDX

Energy dispersive X-ray (Spectroscopy)

EELS Electron energy loss spectroscopy

FIB Focused ion beam

FS Flash sintering

GIF Gatan imaging filter

HRTEM High resolution transmission electron microscopy

MAD Metalorganic aerosol deposition

MEMS Micro electro-mechanical systems

PIPS Precision ion polishing system

SEM Scanning electron microscopy

TEM Transmission electron microscopy

\section{Appendix}

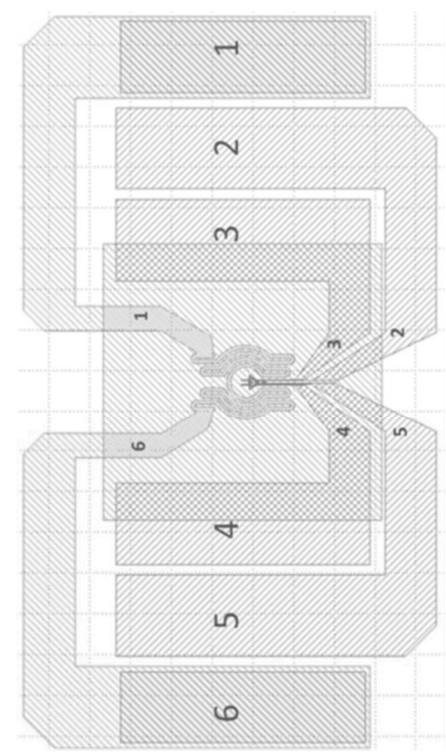

(a)

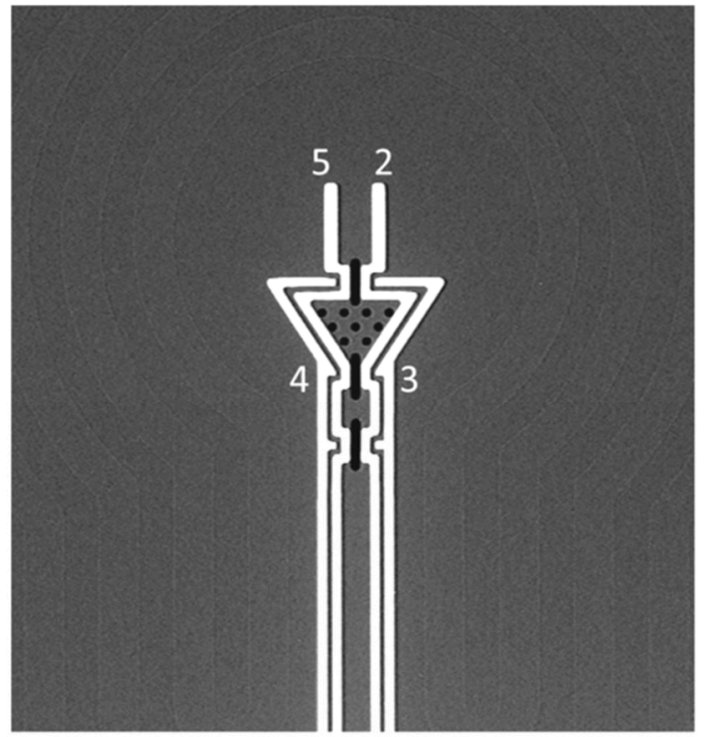

(b)

Figure A1. DENSsolutions MEMS chip. (a) Overview of the two heating $(1,6)$ and four biasing $(2,3,4,5)$ electrodes. (b) Enlarged section of central area of the SiN membrane with the four biasing electrodes on top. Between electrode 2 and 5, the windows (point and line geometry) are visible above which the TEM lamellae will be positioned. Published with permission of the authors [55]. 
Table A1. Step by step protocol for the in-situ lift-out and transfer procedure of a cross-sectional thin film lamella.

\begin{tabular}{cccccccc}
\hline \multirow{2}{*}{$\#$} & \multirow{2}{*}{ Description } & \multicolumn{2}{c}{ Stage Position } & \multicolumn{2}{c}{ Electron Gun } & \multicolumn{2}{c}{ Ion Gun } \\
\cline { 3 - 7 } & & $\mathbf{R}\left[^{\circ}\right]^{-}$ & $\mathbf{T}\left[{ }^{\circ}\right]$ & $\mathbf{V}[\mathbf{k V}]$ & $\mathbf{I}[\mathbf{n A}]$ & $\mathbf{V}[\mathbf{k V}]$ & $\mathbf{I}[\mathbf{p A}]$ \\
\hline 1 & Window milling & 90 & 14 & 5 & 1.6 & 30 & 7000 \\
2 & Cleaning cross section (CSS) bottom & 90 & 15.5 & 5 & 1.6 & 30 & 3000 \\
3 & CSS top & 90 & 12.5 & 5 & 1.6 & 30 & 3000 \\
4 & U-Cut & 270 & 20 & 5 & 1.6 & 30 & 3000 \\
5 & Needle (Omniprobe) drive in & 90 & 14 & 5 & 1.6 & 30 & 10 \\
6 & Mounting on Omniprobe & 90 & 14 & 5 & 1.6 & 30 & 10 \\
7 & Lift-out/Omniprobe retract & 90 & 14 & 5 & 1.6 & 30 & 10 \\
8 & Transfer & 90 & 14 & 10 & 2.1 & 30 & 10 \\
9 & Mounting on chip & 90 & 14 & 10 & 2.1 & 30 & 10 \\
10 & Cutting from Omniprobe & 90 & 14 & 10 & 2.1 & 30 & 300 \\
11 & Thinning, front + back (raw) & 90 & $15.2 / 12.8$ & 10 & 2.1 & 30 & 300 \\
12 & Thinning, front + back (middle) & 90 & $15.2 / 12.8$ & 10 & 2.1 & 30 & 100 \\
13 & Thinning, back + front (smooth) & 90 & $13.3 / 14.7$ & 10 & 2.1 & 30 & 30 \\
14 & Polishing, back + front & 90 & $9 / 19$ & 10 & 2.1 & 5 & 21 \\
\hline
\end{tabular}

\section{References}

1. Cologna, M.; Rashkova, B.; Raj, R. Flash Sintering of Nanograin Zirconia in $<5$ s at $850{ }^{\circ} \mathrm{C}$ : Rapid Communications of the American Ceramic Society. J. Am. Ceram. Soc. 2010, 93, 3556-3559.

2. Downs, J.A.; Sglavo, V.M. Electric Field Assisted Sintering of Cubic Zirconia at $390^{\circ}$ C. J. Am. Ceram. Soc. 2013, 96, 1342-1344. [CrossRef]

3. Lebrun, J.-M.; Raj, R. A First Report of Photoemission in Experiments Related to Flash Sintering. J. Am. Ceram. Soc. 2014, 97, 2427-2430. [CrossRef]

4. Biesuz, M.; Luchi, P.; Quaranta, A.; Martucci, A.; Sglavo, V.M. Photoemission during flash sintering: An interpretation based on thermal radiation. J. Eur. Ceram. Soc. 2017, 37, 3125-3130. [CrossRef]

5. Gonzalez-Julian, J.; Guillon, O. Effect of Electric Field/Current on Liquid Phase Sintering. J. Am. Ceram. Soc. 2015, 98, 2018-2027. [CrossRef]

6. Biesuz, M.; Sglavo, V.M. Current-induced abnormal and oriented grain growth in corundum upon flash sintering. Scr. Mater. 2018, 150, 82-86. [CrossRef]

7. Charalambous, H.; Jha, S.K.; Wang, H.; Phuah, X.L.; Wang, H.; Tsakalakos, T. Inhomogeneous reduction and its relation to grain growth of titania during flash sintering. Scr. Mater. 2018, 155, 37-40. [CrossRef]

8. M'Peko, J.-C.; Francis, J.S.; Raj, R. Field-assisted sintering of undoped $\mathrm{BaTiO}_{3}$ : Microstructure evolution and dielectric permittivity. J. Eur. Ceram. Soc. 2014, 34, 3655-3660. [CrossRef]

9. Nakagawa, Y.; Yoshida, H.; Uehashi, A.; Tokunaga, T.; Sasaki, K.; Yamamoto, T. Electric current-controlled synthesis of $\mathrm{BaTiO}_{3}$. J. Am. Ceram. Soc. 2017, 100, 3843-3850. [CrossRef]

10. Li, J.; Guan, L.; Zhang, W.; Luo, M.; Song, J.; Song, X.; An, S. Sintering behavior of samarium doped ceria under DC electrical field. Ceram. Int. 2018, 44, 2470-2477. [CrossRef]

11. Valdebenito, J.U.; Akbari-Fakhrabadi, A.; Viswanathan, M.R. Effect of flash sintering on microstructure of $\mathrm{Ce}_{0.9} \mathrm{Gd}_{0.1} \mathrm{O}_{1.95}$ electrolyte fabricated by tape-casting. Mater. Lett. 2017, 209, 291-294. [CrossRef]

12. Spiridigliozzi, L.; Biesuz, M.; Dell'Agli, G.; Di Bartolomeo, E.; Zurlo, F.; Sglavo, V.M. Microstructural and electrical investigation of flash-sintered Gd/Sm-doped ceria. J. Mater. Sci. 2017, 52, 7479-7488. [CrossRef]

13. Biesuz, M.; Dell'Agli, G.; Spiridigliozzi, L.; Ferone, C.; Sglavo, V.M. Conventional and field-assisted sintering of nanosized Gd-doped ceria synthesized by co-precipitation. Ceram. Int. 2016, 42, 11766-11771. [CrossRef]

14. Muccillo, R.; Muccillo, E.N.S. Shrinkage control of yttria-stabilized zirconia during ac electric field-assisted sintering. J. Eur. Ceram. Soc. 2014, 34, 3871-3877. [CrossRef]

15. Ji, W.; Parker, B.; Falco, S.; Zhang, J.Y.; Fu, Z.Y.; Todd, R.I. Ultra-fast firing: Effect of heating rate on sintering of 3YSZ, with and without an electric field. J. Eur. Ceram. Soc. 2017, 37, 2547-2551. [CrossRef]

16. Carvalho, S.; Muccillo, E.; Muccillo, R. Electrical Behavior and Microstructural Features of Electric Field-Assisted and Conventionally Sintered 3 moL\% Yttria-Stabilized Zirconia. Ceramics 2018, 1, 2. [CrossRef] 
17. Muccillo, R.; Muccillo, E.N.S. Electric field-assisted flash sintering of tin dioxide. J. Eur. Ceram. Soc. 2014, 34, 915-923. [CrossRef]

18. Dargatz, B.; Gonzalez-Julian, J.; Guillon, O. Effect of electric field and atmosphere on the processing of nanocrystalline ZnO. In Oxide-Based Materials and Devices V; International Society for Optics and Photonics; SPIE: San Francisco, CA, USA, 2014; Volume 8987, p. 89871H.

19. Luo, J. The scientific questions and technological opportunities of flash sintering: From a case study of $\mathrm{ZnO}$ to other ceramics. Scr. Mater. 2018, 146, 260-266. [CrossRef]

20. Nie, J.; Zhang, Y.; Chan, J.M.; Huang, R.; Luo, J. Water-assisted flash sintering: Flashing ZnO at room temperature to achieve $\sim 98 \%$ density in seconds. Scr. Mater. 2018, 142, 79-82. [CrossRef]

21. Nie, J.; Zhang, Y.; Chan, J.M.; Jiang, S.; Huang, R.; Luo, J. Two-step flash sintering of ZnO: Fast densification with suppressed grain growth. Scr. Mater. 2017, 141, 6-9. [CrossRef]

22. Gao, H.; Asel, T.J.; Cox, J.W.; Zhang, Y.; Luo, J.; Brillson, L.J. Native point defect formation in flash sintered $\mathrm{ZnO}$ studied by depth-resolved cathodoluminescence spectroscopy. J. Appl. Phys. 2016, 120, 105302. [CrossRef]

23. Zhang, Y.; Luo, J. Promoting the flash sintering of $\mathrm{ZnO}$ in reduced atmospheres to achieve nearly full densities at furnace temperatures of $<120^{\circ} \mathrm{C}$. Scr. Mater. 2015, 106, 26-29.

24. Zhang, Y.; Jung, J.-I.; Luo, J. Thermal runaway, flash sintering and asymmetrical microstructural development of $\mathrm{ZnO}$ and $\mathrm{ZnO}-\mathrm{Bi}_{2} \mathrm{O}_{3}$ under direct currents. Acta Mater. 2015, 94, 87-100. [CrossRef]

25. Schmerbauch, C.; Gonzalez-Julian, J.; Röder, R.; Ronning, C.; Guillon, O. Flash Sintering of Nanocrystalline Zinc Oxide and its Influence on Microstructure and Defect Formation. J. Am. Ceram. Soc. 2014, 97, 1728-1735. [CrossRef]

26. Todd, R.I. Electrical characteristics of flash sintering: Thermal runaway of Joule heating. J. Eur. Ceram. Soc. 2015, 35, 1865-1877. [CrossRef]

27. da Silva, J.G.P.; Al-Qureshi, H.A.; Keil, F.; Janssen, R. A dynamic bifurcation criterion for thermal runaway during the flash sintering of ceramics. J. Eur. Ceram. Soc. 2016, 36, 1261-1267. [CrossRef]

28. Naik, K.S. Flash sintering as a nucleation phenomenon and a model thereof. J. Eur. Ceram. Soc. 2014, 34, 4063-4067. [CrossRef]

29. Du, Y. Estimating Joule heating and ionic conductivity during flash sintering of 8YSZ. J. Eur. Ceram. Soc. 2016, 36, 749-759. [CrossRef]

30. Zapata-Solvas, E.; Gómez-García, D.; Domínguez-Rodríguez, A.; Todd, R.I. Ultra-fast and energy-efficient sintering of ceramics by electric current concentration. Sci. Rep. 2015, 5, 8513. [CrossRef] [PubMed]

31. Chaim, R. Liquid Film Capillary Mechanism for Densification of Ceramic Powders during Flash Sintering. Materials 2016, 9, 280. [CrossRef] [PubMed]

32. Chaim, R. Particle Surface Softening as Universal Behaviour during Flash Sintering of Oxide Nano-Powders. Materials 2017, 10, 179. [CrossRef]

33. Narayan, J. A new mechanism for field-assisted processing and flash sintering of materials. Scr. Mater. 2013, 69, 107-111. [CrossRef]

34. Wang, J.; Cao, J.; Fang, B.; Lu, P.; Deng, S.; Wang, H. Synthesis and characterization of multipod, flower-like, and shuttle-like $\mathrm{ZnO}$ frameworks in ionic liquids. Mater. Lett. 2005, 59, 1405-1408. [CrossRef]

35. Bacaksiz, E.; Parlak, M.; Tomakin, M.; Özçelik, A.; Karakız, M.; Altunbaş, M. The effects of zinc nitrate, zinc acetate and zinc chloride precursors on investigation of structural and optical properties of $\mathrm{ZnO}$ thin films. J. Alloys Compd. 2008, 466, 447-450. [CrossRef]

36. Schwarz, S.; Thron, A.M.; Rufner, J.; Benthem, K.; Guillon, O. Low Temperature Sintering of Nanocrystalline Zinc Oxide: Effect of Heating Rate Achieved by Field Assisted Sintering/Spark Plasma Sintering. J. Am. Ceram. Soc. 2012, 95, 2451-2457. [CrossRef]

37. Cramer, C.L.; Gonzalez-Julian, J.; Colasuonno, P.S.; Holland, T.B. Continuous functionally graded material to improve the thermoelectric properties of ZnO. J. Eur. Ceram. Soc. 2017, 37, 4693-4700. [CrossRef]

38. Gao, L.; Li, Q.; Luan, W.; Kawaoka, H.; Sekino, T.; Niihara, K. Preparation and Electric Properties of Dense Nanocrystalline Zinc Oxide Ceramics. J. Am. Ceram. Soc. 2004, 85, 1016-1018. [CrossRef]

39. Wang, J.; Gao, L. Photoluminescence Properties of Nanocrystalline ZnO Ceramics Prepared by Pressureless Sintering and Spark Plasma Sintering. J. Am. Ceram. Soc. 2005, 88, 1637-1639. [CrossRef] 
40. Dargatz, B.; Gonzalez-Julian, J.; Bram, M.; Shinoda, Y.; Wakai, F.; Guillon, O. FAST/SPS sintering of nanocrystalline zinc oxide-Part II: Abnormal grain growth, texture and grain anisotropy. J. Eur. Ceram. Soc. 2016, 36, 1221-1232. [CrossRef]

41. Igasaki, Y.; Saito, H. The effects of deposition rate on the structural and electrical properties of $\mathrm{ZnO}: \mathrm{Al}$ films deposited on (1120) oriented sapphire substrates. J. Appl. Phys. 1991, 70, 3613-3619. [CrossRef]

42. Lu, L.; Wong, M. The Resistivity of Zinc Oxide under Different Annealing Configurations and Its Impact on the Leakage Characteristics of Zinc Oxide Thin-Film Transistors. IEEE Trans. Electron Devices 2014, 61, 1077-1084. [CrossRef]

43. Gonzalez-Julian, J.; Neuhaus, K.; Bernemann, M.; Pereira da Silva, J.; Laptev, A.; Bram, M.; Guillon, O. Unveiling the mechanisms of cold sintering of $\mathrm{ZnO}$ at $250{ }^{\circ} \mathrm{C}$ by varying applied stress and characterizing grain boundaries by Kelvin Probe Force Microscopy. Acta Mater. 2018, 144, 116-128. [CrossRef]

44. Donnay, G.; Kihara, K. Anharmonic thermal vibrations in ZnO. Can. Mineral. 1985, 23, 647-654.

45. Moshnyaga, V.; Khoroshun, I.; Sidorenko, A.; Petrenko, P.; Weidinger, A.; Zeitler, M.; Rauschenbach, B.; Tidecks, R.; Samwer, K. Preparation of rare-earth manganite-oxide thin films by metalorganic aerosol deposition technique. Appl. Phys. Lett. 1999, 74, 2842-2844. [CrossRef]

46. Jungbauer, M.; Hühn, S.; Egoavil, R.; Tan, H.; Verbeeck, J.; Van Tendeloo, G.; Moshnyaga, V. Atomic layer epitaxy of Ruddlesden-Popper $\mathrm{SrO}\left(\mathrm{SrTiO}_{3}\right)_{n}$ films by means of metalorganic aerosol deposition. Appl. Phys. Lett. 2014, 105, 251603. [CrossRef]

47. Zintler, A.; Kunz, U.; Pivak, Y.; Sharath, S.U.; Vogel, S.; Hildebrandt, E.; Kleebe, H.-J.; Alff, L.; Molina-Luna, L. FIB based fabrication of an operative Pt/HfO 2 /TiN device for resistive switching inside a transmission electron microscope. Ultramicroscopy 2017, 181, 144-149. [CrossRef]

48. Pérez Garza, H.H.; Zuo, K.; Pivak, Y.; Morsink, D.; Zakhozheva, M.; Pen, M.; van Weperen, S.; Xu, Q. MEMS-Based System for In-Situ Biasing and Heating Solutions inside the TEM. Available online: https: //onlinelibrary.wiley.com/doi/pdf/10.1002/9783527808465.EMC2016.6710 (accessed on 3 April 2019).

49. Zhang, L.; Zhu, L.; Li, X.; Xu, Z.; Wang, W.; Bai, X. Resistive switching mechanism in the one diode-one resistor memory based on $\mathrm{p}+-\mathrm{Si} / \mathrm{n}-\mathrm{ZnO}$ heterostructure revealed by in-situ TEM. Sci. Rep. 2017, 7, 45143. [CrossRef]

50. Jongmanns, M.; Raj, R.; Wolf, D.E. Generation of Frenkel defects above the Debye temperature by proliferation of phonons near the Brillouin zone edge. New J. Phys. 2018, 20, 093013. [CrossRef]

51. Hu, C.; Wang, Q.; Bai, S.; Xu, M.; He, D.; Lyu, D.; Qi, J. The effect of oxygen vacancy on switching mechanism of $\mathrm{ZnO}$ resistive switching memory. Appl. Phys. Lett. 2017, 110, 073501. [CrossRef]

52. Lee, J.S.; Lee, S.; Noh, T.W. Resistive switching phenomena: A review of statistical physics approaches. Appl. Phys. Rev. 2015, 2, 031303. [CrossRef]

53. Madelung, O.; Schulz, M.; Rössler, U. II-VI and I-VII Compounds_Semimagnetic Compounds_Zinc Oxide (ZnO) Debye Temperature, Heat Capacity, Density, Melting Point, Vapor Pressure, Hardness; Landolt-Börnstein-Group III Condensed Matter; Springer: Berlin/Heidelberg, Germany, 1999; ISBN 978-3-540-31359-5.

54. Mishra, T.P.; Avila, V.; Neto, R.R.I.; Brams, M.; Guillon, O.; Raj, R. On the role of Debye temperature in the onset of flash in three oxides. Scr. Mater. 2019, 170, 81-84. [CrossRef]

55. Pivak, Y. Lightning System-Nano-Chip Contacts and Interconnect Unit Connectors Numbering-Manual-Version 1.2; DENSsolutions: Delft, The Netherlands, 2017.

(C) 2019 by the authors. Licensee MDPI, Basel, Switzerland. This article is an open access article distributed under the terms and conditions of the Creative Commons Attribution (CC BY) license (http://creativecommons.org/licenses/by/4.0/). 